\title{
Risk Factors Associated with Loco-Regional Failure after Surgical Resection in Patients with Resectable Pancreatic Cancer
}

\author{
Hyun Ju Kim ${ }^{1}$, Woo Jung Lee ${ }^{2}$, Chang Moo Kang ${ }^{2}$, Ho Kyoung Hwang ${ }^{2}$, Seung Min Bang ${ }^{3}$, \\ Si Young Song ${ }^{3}$, Jinsil Seong ${ }^{1}$ * \\ 1 Department of Radiation Oncology, Yonsei University College of Medicine, Seoul, Korea, 2 Division of \\ Hepatobiliary and Pancreas, Department of Surgery, Yonsei University College of Medicine, Seoul, Korea, \\ 3 Division of Gastroenterology, Department of Internal Medicine, Yonsei University College of Medicine, \\ Seoul, Korea \\ * jsseong@yuhs.ac
}

\section{Abstract}

\section{Purpose}

To evaluate the risk factors associated with loco-regional failure after surgical resection and to identify the subgroup that can obtain benefits from adjuvant radiotherapy (RT).

\section{OPEN ACCESS}

Citation: Kim HJ, Lee WJ, Kang CM, Hwang HK, Bang SM, Song SY, et al. (2016) Risk Factors Associated with Loco-Regional Failure after Surgical Resection in Patients with Resectable Pancreatic Cancer. PLoS ONE 11(6): e0157196. doi:10.1371/ journal.pone.0157196

Editor: William B. Coleman, University of North Carolina School of Medicine, UNITED STATES

Received: April 15, 2016

Accepted: May 25, 2016

Published: June 22, 2016

Copyright: $\odot 2016 \mathrm{Kim}$ et al. This is an open access article distributed under the terms of the Creative Commons Attribution License, which permits unrestricted use, distribution, and reproduction in any medium, provided the original author and source are credited.

Data Availability Statement: All relevant data are within the paper.

Funding: The authors have no support or funding to report.

Competing Interests: The authors have declared that no competing interests exist.

\section{Materials and Methods}

We identified patients treated with surgical resection for resectable pancreatic cancer at Severance hospital between January 1993 and December 2014. Patients who received any neoadjuvant or adjuvant RT were excluded. A total of 175 patients were included. Adjuvant chemotherapy was performed in 107 patients with either a gemcitabine-based regimen $(65.4 \%)$ or 5 -FU based one (34.9\%).

\section{Results}

The median loco-regional failure-free survival (LRFFS) and overall survival (OS) were 23.9 and 33.6 months, respectively. A recurrence developed in 108 of 175 patients (61.7\%). The predominant pattern of the first failure was distant $(42.4 \%)$ and 47 patients $(26.9 \%)$ developed local failure as the first site of recurrence. Multivariate analysis identified initial CA 19$9 \geq 200 \mathrm{U} / \mathrm{mL}$, N1 stage, perineural invasion (PNI), and resection margin as significant independent risk factors for LRFFS. Patients were divided into four groups according to the number of risk factors, including initial CA 19-9, N stage, and PNI. Patients exhibiting two risk factors had 3.2-fold higher loco-regional failure $(P<0.001)$ and patients with all risk factors showed a 6.5 -fold increase $(P<0.001)$ compared with those with no risk factors. In the analysis for OS, patients with more than two risk factors also had 3.3- to 6-fold higher risk of death with statistical significance. 


\section{Conclusion}

The results suggest that patients who exhibit more than two risk factors have a higher risk of locoregional failure and death. This subgroup could be benefited by the effective local adjuvant treatment.

\section{Introduction}

Pancreatic cancer is a fatal malignant disease and the fifth leading cause of cancer death in Korea. [1] Surgical resection is thought to be the only curative treatment option for localized pancreatic cancer, but only $10-15 \%$ of pancreatic cancer patients are resectable at presentation. Even the median survival is only 10-18 months after surgery alone.[2-5] Most treatment failures occur within 1-2 years after surgery in local recurrence, hepatic metastases, or both.[6,7] Systemic and local adjuvant treatment have been investigated to define their effects. In the Gastrointestinal Tumor Study Group (GITSG) trial,[8,9] median survival for the adjuvant chemoradiotherapy (CRT) group was significantly longer than that observed for the control group (20 months vs. 11 months). However, the European Organization for Research and Treatment of Cancer (EORTC) 40891 trial did not show a statistically significant difference in progression-free survival (PFS) and overall survival (OS) between two arms.[10,11] To clarify the effect of adjuvant CRT, the European Study Group for Pancreatic Cancer (ESPAC-1) trial was performed. Results from the ESPAC-1 trial suggested that adjuvant CRT has a detrimental effect on survival compared with surgery alone.[12,13] Conclusions drawn from the ESPAC-1 trial have raised questions about the efficacy of adjuvant CRT for locally advanced pancreatic cancer, and consequently, current clinical practices tend to exclude adjuvant radiotherapy (RT) from routine adjuvant treatment modalities.

In the clinical setting, however, loco-regional failures as the first recurrence are frequent, resulting in an additional course of RT as a salvage treatment. While consensus regarding the benefit of adjuvant RT is lacking, this study was designed to evaluate the risk factors associated with loco-regional failure after surgical resection and to identify the subgroup of patients who can benefit most from adjuvant RT.

\section{Materials and Methods}

\section{Study population}

We searched to identify all patients treated with surgical resection for pancreatic cancer at Severance hospital from 1993 to 2014. A total of 411 patients were identified and retrospectively reviewed. Among these patients, 236 were excluded from this analysis due to the following reasons: (1) receipt of neoadjuvant CRT before surgical resection. $(\mathrm{n}=78)$; (2) receipt of surgical resection as a palliative aim for stage IV disease $(n=24)$; (3) receipt of postoperative CRT or RT $(n=39)$; (4) diagnosed with neuroendocrine tumor $(n=60)$, intraductal papillary neoplasm (IPMN) without invasiveness $(\mathrm{n}=9)$, and solid pseudopapillary tumor $(\mathrm{n}=10)$; (5) exhibited history of another primary cancer $(\mathrm{n}=5)$; and (6) follow-up after surgical resection was not performed $(\mathrm{n}=11)$. Ultimately, a total of 175 patients were included for this analysis. This study was approved by Institutional review board (IRB) of Yonsei University Health System. The patient records/information was anonymized and de-identified prior to analysis, and informed consent was not obtained from each participants.

\section{Preoperative assessment and treatment}

Pretreatment evaluation included a review of previous medical history, physical examination, laboratory tests and performance status. For staging workup, preoperative computerized 
tomography, magnetic resonance image, and 18F-fluorodeoxyglucose positron emission tomography-CT were performed.

Resectability was assessed based on imaging studies according to the National Comprehensive Cancer Network (NCCN) classification.[14] Resectable pancreatic cancer was defined as: (1) the absence of distant metastasis, (2) no evidence of tumor invasion to the SMA or celiac axis, and (3) none or less than 180 degree contact with superior mesenteric vein (SMV) or portal vein (PV) without contour irregularity. Vascular invasion was defined as tumor-to-vessel circumferential contiguity, either abutment ( $\leq 50 \%$ of the circumference) or encasement ( $>50 \%$ of the circumference).

Surgical procedures were composed of pylorus-preserving pancreaticoduodenectomy (PPPD), Whipple operation, or total pancreatectomy for pancreatic head cancer and partial pancreatectomy for a pancreatic body and tail cancer. Surgical margins such as the pancreatic duct, bile duct, retroperitoneal margin, duodenum, or stomach were evaluated grossly and microscopically to elucidate the status of the surgical margins. These surgical margins, with the exception of the retroperitoneal margin, were often evaluated using frozen-section analysis, and if positive, additional resection was performed. The final margin status was reported in the permanent pathology report. Resection status was defined as complete resection with microscopically negative margins (R0), grossly complete resection with microscopically positive margins (R1), and grossly incomplete resection (R2), which is determined by surgeons or on the postoperative imaging studies. Adjuvant chemotherapy was performed in 107 patients (61.1\%) with either a gemcitabine-based regimen (70 patients, $65.4 \%$ ) or 5-FU-based one (37 patients, 34.6\%).

The following variables were collected for each patient: patient demographics (age, sex, diabetes mellitus (DM), Eastern Cooperative Oncology Group (ECOG) performance status), tumor characteristics (size, stage, tumor marker, grade, lymphovascular invasion (LVI), perineural invasion (PNI), lymph node (LN) metastasis, perinodal extension (PNE)), and pathologic margin status.

\section{Statistical analysis}

Study endpoints were loco-regional failure-free survival (LRFFS) and OS. Survival duration was calculated from the date of surgical resection to the corresponding event (loco-regional failure, distant metastasis, or death). We performed Pearson's chi-squared test or Fisher's exact test to compare categorical variables. The area under the receiver-operating characteristic (ROC) curve (AUC) was used to find optimal cut off value for preoperative CA 19-9 level. The Kaplan-Meier method with log-rank test was used to analyze survival outcomes. Stepwise Cox proportional hazards regression was used to perform a multivariable analysis on prognostic factors for LRFFS and OS (inclusion criteria $\mathrm{P}<0.05$ ). All statistical tests were two-sided with significance defined as $\mathrm{P}<0.05$. The data were analyzed using IBM SPSS software version 20.0 (SPSS Inc., Chicago, IL, USA).

\section{Results}

\section{Patient characteristics}

A total of 175 patients were included in this study. The patient characteristics are summarized in Table 1 . The median age was 65 years (range, $34-84$ years). ECOG performance status was 0 in 96 patients (54.9\%) or 1 in 79 patients (45.1\%). Among 122 pancreatic head cancer patients, 101 (58\%) received PPPD, 19 (11\%) received Whipple's operation, and 2 (1\%) received total pancreatectomy. Fifty-three patients with pancreatic body or tail cancer received partial pancreatectomy. Most of the patients were diagnosed with ductal adenocarcinoma (144 patients), while mucinous carcinoma, acinar cell carcinoma, and IPMN with invasion were diagnosed in 6, 4, and 21 patients, respectively. One-hundred forty three patients were diagnosed with T3 
Table 1. Patient characteristics.

\begin{tabular}{|c|c|c|}
\hline \multirow{3}{*}{$\begin{array}{l}\text { Characteristics } \\
\text { Age, mean (range), yr } \\
\text { Sex }\end{array}$} & n & \multirow[t]{2}{*}{$\%$} \\
\hline & $63.3(34-84)$ & \\
\hline & & \\
\hline Male & 108 & 61.7 \\
\hline Female & 67 & 38.3 \\
\hline \multicolumn{3}{|l|}{ ECOG performance status } \\
\hline 0 & 96 & 54.9 \\
\hline 1 & 79 & 45.1 \\
\hline \multicolumn{3}{|l|}{ Tumor location } \\
\hline Head & 122 & 69.7 \\
\hline Body & 36 & 20.6 \\
\hline Tail & 17 & 9.7 \\
\hline \multicolumn{3}{|l|}{ Operation name } \\
\hline PPPD & 101 & 57.7 \\
\hline Whipple operation & 19 & 10.9 \\
\hline Total pancreatectomy & 2 & 1.1 \\
\hline Partial pancreatectomy & 53 & 30.3 \\
\hline \multicolumn{3}{|l|}{ Pathology } \\
\hline Ductal adenoca & 144 & 82.3 \\
\hline Mucinous adenoca & 6 & 3.4 \\
\hline Acinar cell ca & 4 & 2.3 \\
\hline IPMN c invasiveness & 21 & 12.0 \\
\hline \multicolumn{3}{|l|}{ T stage } \\
\hline $\mathrm{T} 1$ & 11 & 6.3 \\
\hline $\mathrm{T} 2$ & 14 & 8.0 \\
\hline T3 & 143 & 81.7 \\
\hline $\mathrm{T} 4$ & 7 & 4.0 \\
\hline \multicolumn{3}{|l|}{$\mathrm{N}$ stage } \\
\hline No & 88 & 50.3 \\
\hline $\mathrm{N} 1$ & 87 & 49.7 \\
\hline \multicolumn{3}{|l|}{ Stage } \\
\hline 1 & 21 & 12.0 \\
\hline IIA & 67 & 38.3 \\
\hline IIB & 81 & 46.3 \\
\hline III & 6 & 3.4 \\
\hline \multicolumn{3}{|l|}{ Grade } \\
\hline WD & 19 & 10.9 \\
\hline MD & 108 & 61.7 \\
\hline PD-UD & 15 & 8.5 \\
\hline Unknown & 33 & 18.9 \\
\hline \multicolumn{3}{|l|}{ Tumor size } \\
\hline$<3 \mathrm{~cm}$ & 102 & 58.3 \\
\hline$\geq 3 \mathrm{~cm}$ & 73 & 41.7 \\
\hline \multicolumn{3}{|l|}{ LVI } \\
\hline No & 121 & 69.1 \\
\hline Yes & 54 & 30.9 \\
\hline \multicolumn{3}{|l|}{ PNI } \\
\hline No & 66 & 37.7 \\
\hline
\end{tabular}


Table 1. (Continued)

\begin{tabular}{l|r|r}
\hline Characteristics & $\mathbf{n}$ & $\%$ \\
\hline Yes & 109 & 62.3 \\
\hline Resection status & & \\
\hline R0 & 160 & 91.4 \\
\hline R1 & 15 & 8.6 \\
\hline PNE & & \\
\hline No & 149 & 85.1 \\
\hline Yes & 26 & 14.9 \\
\hline Preoperative CA 19-9 & & 63.4 \\
\hline$\geq 200 \mathrm{U} / \mathrm{mL}$ & 111 & 36.6 \\
\hline$<200 \mathrm{U} / \mathrm{mL}$ & 64 & \\
\hline Postoperative CA 19-9 & & 74.2 \\
\hline$\geq 40 \mathrm{U} / \mathrm{mL}$ & 130 & 22.9 \\
\hline$<40 \mathrm{U} / \mathrm{mL}$ & 40 & 2.9 \\
\hline Unknown & 5 & \\
\hline
\end{tabular}

Abbreviations: $\mathrm{ECOG}=$ Eastern Cooperative Oncology Group; PPPD = pylorus preserving pancreaticoduodenectomy; IPMN = Intraductal papillary mucinous neoplasm; WD = well-differentiated; $\mathrm{MD}$ = moderately-differentiated; $\mathrm{PD}=$ poorly-differentiated; $\mathrm{UD}=$ undifferentiated $\mathrm{LVI}=$ lymphovascular invasion; $\mathrm{PNI}=$ perineural invasion; $\mathrm{RM}=$ resection margin; $\mathrm{PNE}=$ perinodal extension.

doi:10.1371/journal.pone.0157196.t001

stage based on their pathologic reports. Seven patients were diagnosed with T4 stage, which was initially considered as resectable disease in the preoperative imaging studies. Eighty-seven patients (49.7\%) presented with positive nodal status. Resection status was R0 in 160 patients and R1 in 15 patients. The preoperative and postoperative CA 19-9 level ranged from 0.1 to $20,000 \mathrm{U} / \mathrm{mL}$, with a median of $90.3 \mathrm{U} / \mathrm{mL}$ and 0.1 to $2060 \mathrm{U} / \mathrm{mL}$, with a median of $12.9 \mathrm{U} / \mathrm{mL}$, respectively. The AUC was 0.588 (95\% Confidence interval (CI) 0.504-0.672, P = 0.046) for preoperative CA $19-9$ level and 0.541 (95\% CI 0.454-0.627, $\mathrm{P}=0.362$ ) for postoperative CA 19-9 level. Patients were divided by the cutoff value of $200 \mathrm{U} / \mathrm{mL}$ for preoperative CA 19-9 and $40 \mathrm{U} / \mathrm{mL}$ for postoperative CA 19-9.

\section{Survival outcomes and patterns of failure}

With a median follow-up period of 21 months (range 4.0-109.2 months), 108 out of 175 patients (61.7\%) developed a recurrence. Median time to first failure was 14 months. The cumulative actuarial rates of any recurrence at 12 and 18 months were $41.6 \%$ and $56.5 \%$, respectively. The median LRFFS was 23.9 months and the median OS was 33.6 months with a 5-yr survival rate of $41.5 \%$.

The patterns of failure are summarized in Table 2. Initial sites of failure were composed of local failures (26.9\%), regional failures (5.7\%), and distant metastasis (42.4\%), when counting recurrences in the multiple sites separately. The predominant pattern of the first failure was distant metastasis, mainly in the liver $(n=50)$, peritoneum $(n=14)$, lung $(n=10)$, paraaortic lymph node $(n=3)$, and bone $(n=2)$. Among those who had a distant failure, 52 patients experienced distant failure only. Loco-regional failure without distant metastasis as a first site of recurrence developed in 31 patients (17.7\%).

\section{Risk factors related to LRRF and OS}

We analyzed the prognostic factors related to LRFFS and OS (Table 3). In the univariate analysis, ECOG performance status, preoperative CA 19-9 ( $\geq 200 \mathrm{U} / \mathrm{mL})$, postoperative CA 19-9 
Table 2. Patterns of failure.

\begin{tabular}{|c|c|c|}
\hline \multicolumn{2}{|c|}{ Failure pattern } & \multirow{2}{*}{\begin{tabular}{|c|} 
No (\%) \\
$47(26.9)$ \\
\end{tabular}} \\
\hline Local & & \\
\hline & Local only & $27(15.4)$ \\
\hline & Local \& regional & $2(1.2)$ \\
\hline & Local \& distant & $16(9.1)$ \\
\hline & Local \& regional \& distant & $2(1.2)$ \\
\hline \multirow[t]{3}{*}{ Regional } & & $11(6.3)$ \\
\hline & Regional only & $3(1.7)$ \\
\hline & Regional and distant & $4(0.6)$ \\
\hline \multirow[t]{2}{*}{ Distant } & & $74(42.4)$ \\
\hline & Distant only & $52(29.7)$ \\
\hline
\end{tabular}

doi:10.1371/journal.pone.0157196.t002

( $\geq 40 \mathrm{U} / \mathrm{mL}$ ), N stage, AJCC stage, LVI, PNI, resection margin, and PNE were associated with LRFFS with statistical significance. Among these, preoperative CA 19-9, N stage, PNI, and resection margin were analyzed as independent prognostic factors for LRFFS in multivariate analysis (Fig 1). Then, all patients were divided into four groups according to the number of risk factors they possessed among these three factors: preoperative CA 19-9 ( $\geq 200 \mathrm{U} / \mathrm{mL}), \mathrm{N}$ stage, and PNI. Because positive resection margin is already known as a prognostic factor that requires adjuvant $\mathrm{RT}$, resection margin was not counted as a risk factor in the following analysis. Group 0 was defined as patients who did not exhibit any risk factors, group 1 was defined as those who had one risk factor, and group 2 was defined as those who possessed two risk factors. Group 3 was defined as patients who displayed all three risk factors.

LRFFS showed statistically significant differences according to the number of risk factors that patients exhibited (Fig 2A). No significant difference was shown between groups 0 and 1 (Hazard ratio (HR) 1.73, P =0.133), while groups 2 and 3 showed significant differences in LRFFS compared with group 0. Patients in group 2 had a 3.2-fold higher risk of loco-regional failure ( $\mathrm{P}<0.001,95 \% \mathrm{CI} 1.66-6.06)$ and patients in group 3 had a 6.5 -fold higher risk $(\mathrm{P}<0.001,95 \% \mathrm{CI} 3.12-13.45)$ compared with those in group 0 .

For OS, age ( $<65$ years), preoperative CA $19-9(\geq 200 \mathrm{U} / \mathrm{mL})$, postoperative CA 19-9 ( $\geq 40 \mathrm{U} / \mathrm{mL}$ ), N stage, AJCC stage, LVI, PNI, resection margin, and PNE were shown to be prognostic factors with statistical significance in univariate analysis. In multivariate analysis, $\mathrm{N}$ stage, PNI, and resection margin were independant prognostic factors associated with survival, which were same as in LRFFS.

We investigated whether the same groups as defined by the number of risk factors used in the LRFFS analysis would align with OS. Our data demonstrated that OS also appeared to decrease sequentially in accordance with the higher number of risk factors (Fig 2B). Patients in group 2 had a 3.3-fold higher risk for death $(\mathrm{P}=0.001)$. Group 3, consisted of those who displayed all three risk factors, showed a 6-fold higher risk for death compared with group 0 $(\mathrm{P}<0.001)$. However, patients in group 1 showed a 2 -fold higher tendency for death $(\mathrm{P}=0.109)$.

\section{Discussion}

In this study, we analyzed the patterns of first failure in patients with resected pancreatic cancer and investigated risk factors associated with LRFFS and OS. The purpose of this study was to identify the subgroup that can benefit most from adjuvant RT. Among the patient demographics and clinical-pathological factors, preoperative CA 19-9 $\geq 200 \mathrm{U} / \mathrm{mL}, \mathrm{N}$ stage, and PNI were significant prognostic factors associated with loco-regional failure. LRFFS and OS showed 
Table 3. Prognostic factors for locoregional failure-free survival (LRFFS) and overall survival (OS).

\begin{tabular}{|c|c|c|c|c|c|c|}
\hline & \multicolumn{6}{|c|}{ LRFFS } \\
\hline & & UVA & & & MVA & \\
\hline Characteristic & HR & $95 \% \mathrm{Cl}$ & $\mathbf{P}$ & HR & $95 \% \mathrm{Cl}$ & $\mathbf{P}$ \\
\hline $\begin{array}{l}\text { Age, years (< } 65 \text { vs. } \\
\geq 65)\end{array}$ & 1.258 & $0.85-1.87$ & 0.258 & & & \\
\hline $\begin{array}{l}\text { Sex (male vs. } \\
\text { female) }\end{array}$ & 0.917 & $0.61-1.38$ & 0.674 & & & \\
\hline $\begin{array}{l}\text { Diabetes mellitus } \\
\text { (no vs. yes) }\end{array}$ & 1.014 & $0.67-1.53$ & 0.947 & & & \\
\hline $\begin{array}{l}\text { ECOG performance } \\
\text { status (0 vs. } 1)\end{array}$ & 1.58 & $1.06-2.35$ & 0.023 & 1.315 & $0.86-2.01$ & 0.206 \\
\hline $\begin{array}{l}\text { Preop CA 19-9 } \\
\qquad \begin{array}{l}(<200 \mathrm{U} / \mathrm{mL} \text { vs. } \\
\geq 200 \mathrm{U} / \mathrm{mL})\end{array}\end{array}$ & 2.02 & $1.35-3.02$ & $<0.001$ & 1.738 & $1.04-2.92$ & 0.037 \\
\hline $\begin{array}{l}\text { Postop CA 19-9 } \\
\qquad \begin{array}{l}(<40 \mathrm{U} / \mathrm{mL} \text { vs. } \\
\geq 40 \mathrm{U} / \mathrm{mL})\end{array}\end{array}$ & 1.789 & $1.15-2.79$ & 0.01 & 0.996 & $0.57-1.73$ & 0.99 \\
\hline $\begin{array}{l}\text { Tumor size }(<3 \mathrm{~cm} \\
\text { vs. } \geq 3 \mathrm{~cm})\end{array}$ & 0.756 & $0.50-1.14$ & 0.185 & & & \\
\hline $\begin{array}{l}\text { T stage (T1-2 vs. } \\
\text { T3-4) }\end{array}$ & 1.932 & $1.03-3.64$ & 0.041 & 1.048 & $0.48-2.31$ & 0.908 \\
\hline $\mathrm{N}$ stage (N0 vs. N1) & 2.412 & $1.60-3.64$ & $<0.001$ & 1.661 & $1.03-2.69$ & 0.04 \\
\hline $\begin{array}{l}\text { Grade (WD-MD vs. } \\
\text { PD-UD) }\end{array}$ & 0.953 & $0.48-1.90$ & 0.891 & & & \\
\hline LVI (no vs. yes) & 1.643 & $1.09-2.48$ & 0.018 & 1.134 & $0.72-1.79$ & 0.589 \\
\hline PNI (no vs. yes) & 1.975 & $1.28-3.06$ & 0.002 & 1.813 & $1.09-3.01$ & 0.021 \\
\hline $\begin{array}{l}\text { Resection margin } \\
\text { (R0 vs. R1) }\end{array}$ & 2.101 & $1.14-3.87$ & 0.017 & 1.99 & $1.04-3.81$ & 0.037 \\
\hline PNE (no vs. yes) & 2.547 & $1.53-4.23$ & $<0.001$ & 1.57 & $0.88-2.82$ & 0.13 \\
\hline \multirow[t]{3}{*}{$\begin{array}{l}\text { Chemotherapy (no } \\
\text { vs. yes) }\end{array}$} & 1.053 & $0.70-1.59$ & 0.805 & & & \\
\hline & \multicolumn{6}{|c|}{ os } \\
\hline & & UVA & & & MVA & \\
\hline Characteristic & HR & $95 \% \mathrm{Cl}$ & $\mathbf{P}$ & HR & $95 \% \mathrm{Cl}$ & $\mathbf{P}$ \\
\hline $\begin{array}{l}\text { Age, years (<65 vs. } \\
\quad \geq 65)\end{array}$ & 1.648 & $1.06-2.56$ & 0.027 & 1.489 & $0.94-2.37$ & 0.093 \\
\hline $\begin{array}{l}\text { Sex (male vs. } \\
\text { female) }\end{array}$ & 0.93 & $0.60-1.45$ & 0.749 & & & \\
\hline $\begin{array}{l}\text { Diabetes mellitus } \\
\text { (no vs. yes) }\end{array}$ & 0.947 & $0.60-1.50$ & 0.816 & & & \\
\hline $\begin{array}{l}\text { ECOG performance } \\
\text { status (0 vs. 1) }\end{array}$ & 1.373 & $0.89-2.13$ & 0.157 & & & \\
\hline $\begin{array}{l}\text { Preop CA 19-9 } \\
\qquad \begin{array}{l}(<200 \mathrm{U} / \mathrm{mL} \text { vs. } \\
\geq 200 \mathrm{U} / \mathrm{mL})\end{array}\end{array}$ & 1.891 & $1.22-2.94$ & 0.005 & 1.375 & $0.77-2.45$ & 0.28 \\
\hline $\begin{array}{l}\text { Postop CA 19-9 } \\
\qquad \begin{array}{l}(<40 \mathrm{U} / \mathrm{mL} \text { vs. } \\
\geq 40 \mathrm{U} / \mathrm{mL})\end{array}\end{array}$ & 2.034 & $1.26-3.29$ & 0.004 & 1.289 & $0.72-2.33$ & 0.398 \\
\hline $\begin{array}{l}\text { Tumor size }(<3 \mathrm{~cm} \\
\text { vs. } \geq 3 \mathrm{~cm})\end{array}$ & 0.829 & $0.53-1.30$ & 0.416 & & & \\
\hline $\begin{array}{l}\text { T stage (T1-2 vs. } \\
\text { T3-4) }\end{array}$ & 1.658 & $0.87-3.16$ & 0.125 & & & \\
\hline N stage (N0 vs. N1) & 2.439 & $1.55-3.83$ & $<0.001$ & 1.897 & $1.15-3.13$ & 0.012 \\
\hline
\end{tabular}


Table 3. (Continued)

\begin{tabular}{|c|c|c|c|c|c|c|}
\hline $\begin{array}{l}\text { Grade (WD-MD vs. } \\
\text { PD-UD) }\end{array}$ & 0.943 & $0.43-2.06$ & 0.883 & & & \\
\hline LVI (no vs. yes) & 1.911 & $1.21-3.02$ & 0.006 & 1.413 & $0.85-2.34$ & 0.181 \\
\hline PNI (no vs. yes) & 2.011 & $1.25-3.25$ & 0.004 & 1.838 & $1.08-3.12$ & 0.024 \\
\hline $\begin{array}{l}\text { Resection margin } \\
\text { (R0 vs. R1) }\end{array}$ & 2.305 & $1.18-4.51$ & 0.015 & 2.113 & $1.02-4.36$ & 0.043 \\
\hline PNE (no vs. yes) & 2.165 & $1.20-3.92$ & 0.011 & 1.13 & $0.57-2.26$ & 0.729 \\
\hline $\begin{array}{l}\text { Chemotherapy (no } \\
\text { vs. yes) }\end{array}$ & 0.978 & $0.62-1.53$ & 0.921 & & & \\
\hline
\end{tabular}

doi:10.1371/journal.pone.0157196.t003

significant differences between groups defined by the number of these risk factors they possessed. Patients with more than two risk factors had a 3.2- to 6.5-fold higher risk of locoregional failure, as well as a 3.3- to 6-fold higher risk of death with statistical significance. Thus, we suggest that adjuvant radiotherapy could be beneficial for patients who have two risk factors or more.

Our results are concordant with other prior data that demonstrated distant metastases as the primary pattern of failure in this patient population. In our study, about $42 \%$ of patients experienced distant metastasis and loco-regional failures occurred in $33.2 \%$ of patients. Similarly, in the study from Johns Hopkins hospital, $68.9 \%$ of patients developed distant disease and $31 \%$ of patients developed local failure as the first recurrence.[15] The experimental arm of the CONKO-001 trial, which was assigned to receive gemcitabine after resection, experienced distant metastasis rates of $56 \%$ and local failure rates of 34\%.[16]

In the current practice of surgical resection followed by adjuvant chemotherapy, $60-70 \%$ of patients still experienced recurrences after surgical resection.[15,16] To improve outcomes, several studies have been performed to find the optimal adjuvant treatment. In the GITSG trial, adjuvant CRT showed a significant benefit on survival; however, this study has been criticized for the small number of patients evaluated $(n=43)$. [8,9] The EORTC 40891 phase III trial was performed in Europe to investigate the effect of adjuvant RT with 5-FU. According to this study, those who underwent adjuvant CRT had no significant improvement in survival compared with those who received surgery alone.[10,11] In line with the GITSG and EORTC trials, the ESPAC-1 trial was performed to demonstrate the effect of adjuvant CRT. Results from the ESPAC-1 trial showed a deleterious effect of adjuvant CRT on survival (median 15.9 vs. 17.9 months, $P=0.05$ ), whereas adjuvant chemotherapy had a significant survival benefit (median 20.1 vs. 15.5 months, $\mathrm{P}=0.009$ ). [12,13] Based on the ESPAC-1 trial, current practice was changed to omit adjuvant RT for patients with resected pancreatic cancer. However, the ESPAC-1 trial has also been criticized due to its study design and quality control.[17,18] The $2 \times 2$ factorial design is inappropriate to make a decisive conclusion about the effect of adjuvant CRT. Indeed, $33 \%$ of those assigned to receive chemotherapy did not complete their chemotherapy regimen. Moreover, $17 \%$ of the patients did not receive chemotherapy at all. With respect to RT techniques, $40 \mathrm{~Gy}$ given in a split-course is no longer used in current practice. Radiation field, dosimetry specifications, and overall quality assurance were not described.

To clarify the benefit of adjuvant CRT, several retrospective studies were performed.[19-23] A retrospective study from the Mayo Clinic that included 472 patients investigated outcomes after surgery alone versus surgery plus adjuvant CRT. OS was better in patients who received adjuvant CRT (median OS, 25.2 vs. 19.2 months, $\mathrm{P}=0.001$ ).[19] Another large collaborative study from the Johns Hopkins Hospital and Mayo Clinic [20] showed a survival benefit from adjuvant 5-FU-based CRT compared with surgery alone (median 21.1 vs. 15.5 months, 
(a)

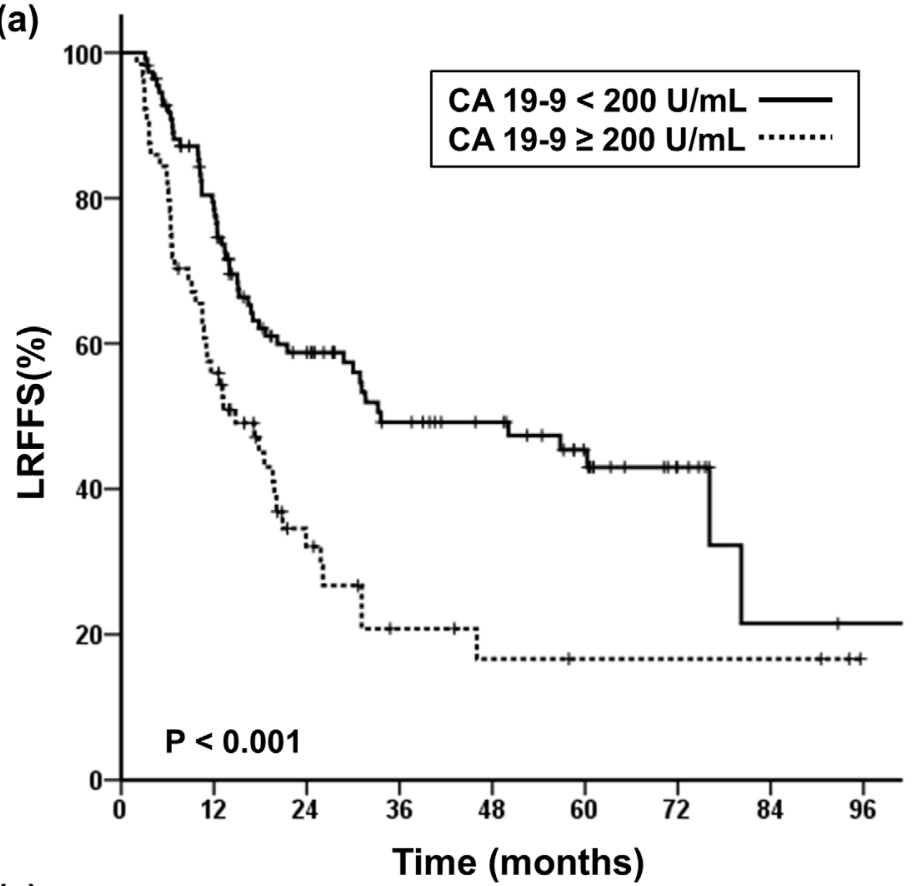

(c)

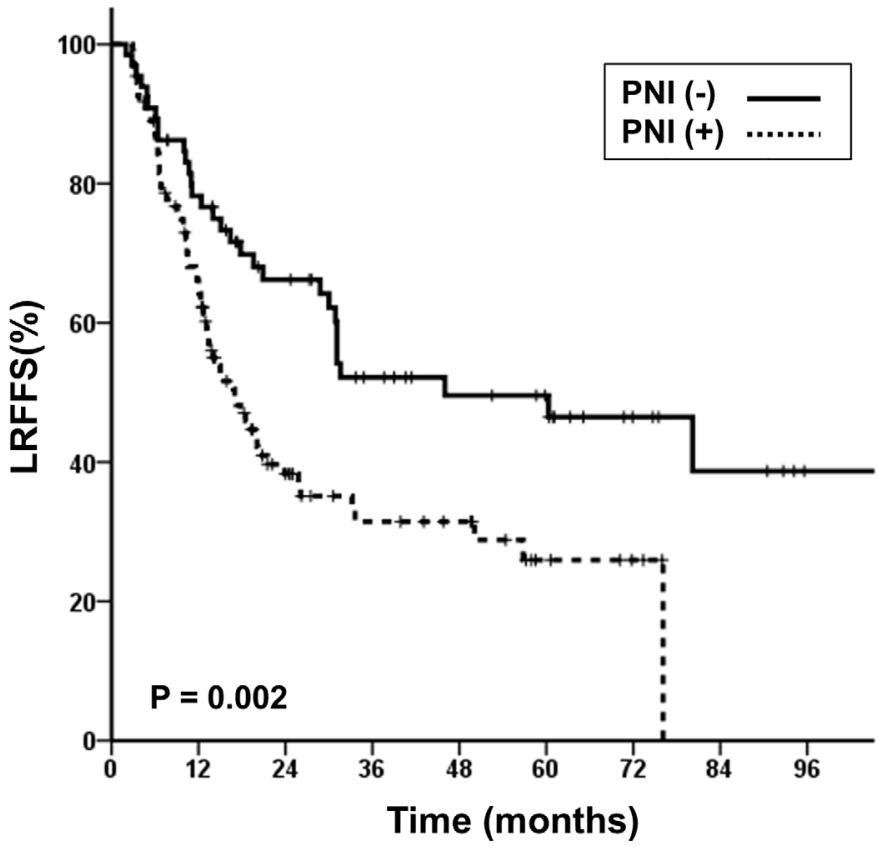

(b)
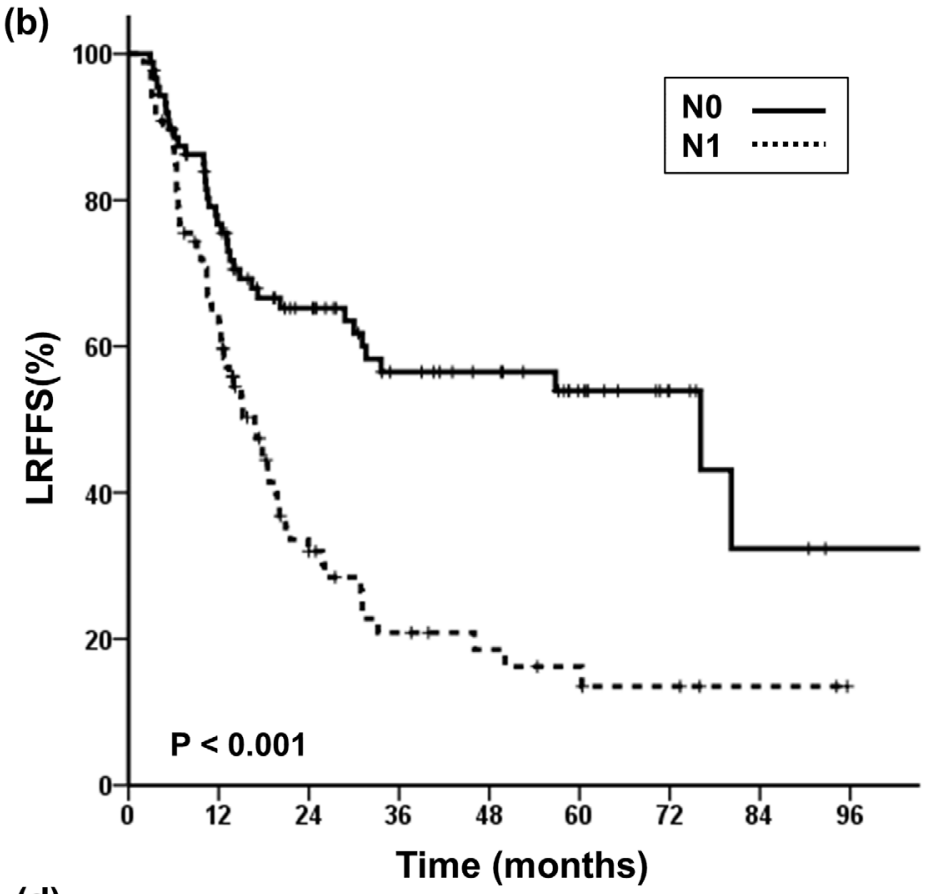

(d)

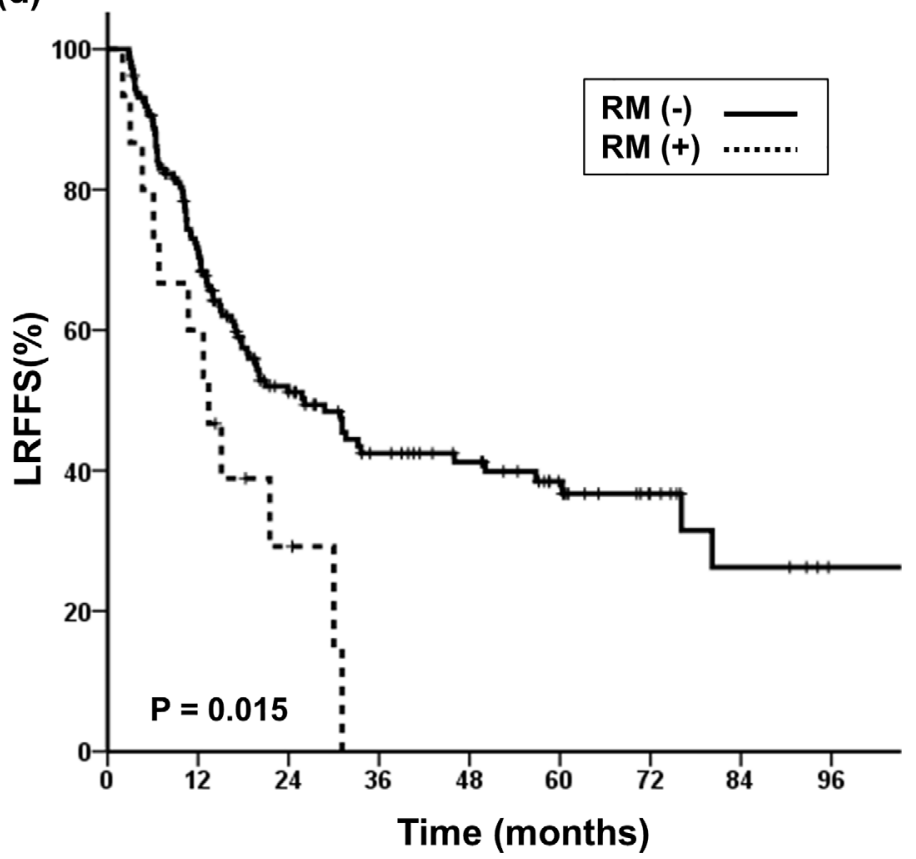

Fig 1. Prognostic factors associated with Loco-regional failure-free survival (LRFFS). Kaplan-Meier curves of Loco-regional failure-free survival (LRFFS) stratified by (a) Initial CA 19-9, (b) N stage, (c) Perineural invasion (PNI) and (d) Resection margin.

doi:10.1371/journal.pone.0157196.g001

$\mathrm{P}<0.001)$. In an analysis of the National Cancer Data Base (NCDB), 6165 patients with pT13N0-1M0 pancreatic adenocarcinoma were categorized into two groups, namely adjuvant CRT and adjuvant chemotherapy, and the outcome was assessed to provide a modern estimate of comparative effectiveness. Adjuvant CRT was independently associated with improved OS compared with adjuvant chemotherapy (median 22.3 vs. 20.0 months, $\mathrm{P}=0.001$ ).[23] The benefit of adjuvant RT with modern techniques is still controversial and the subgroup that can 
(a)

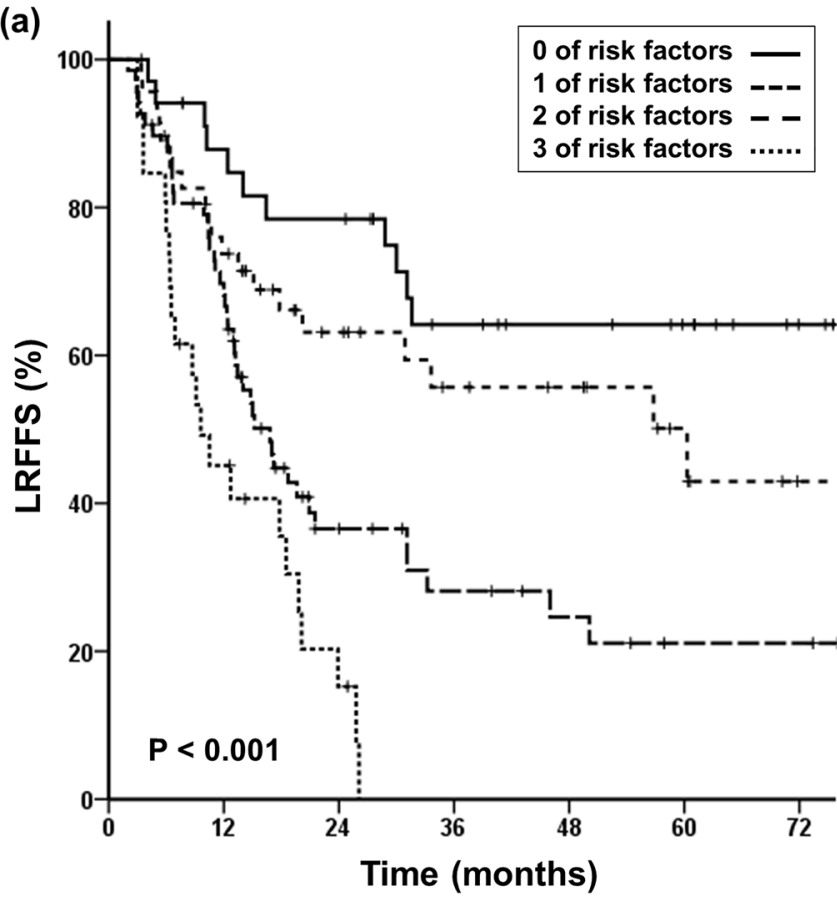

Patients at risk

$\begin{array}{cccccccc}\text { Group 0 } & 35 & 28 & 25 & 17 & 14 & 11 & 5 \\ \text { Group 1 } & 46 & 33 & 20 & 14 & 12 & 7 & 2 \\ \text { Group 2 } & 68 & 44 & 15 & 10 & 7 & 4 & 4 \\ \text { Group 3 } & 26 & 11 & 3 & 0 & 0 & 0 & 0\end{array}$

(b)

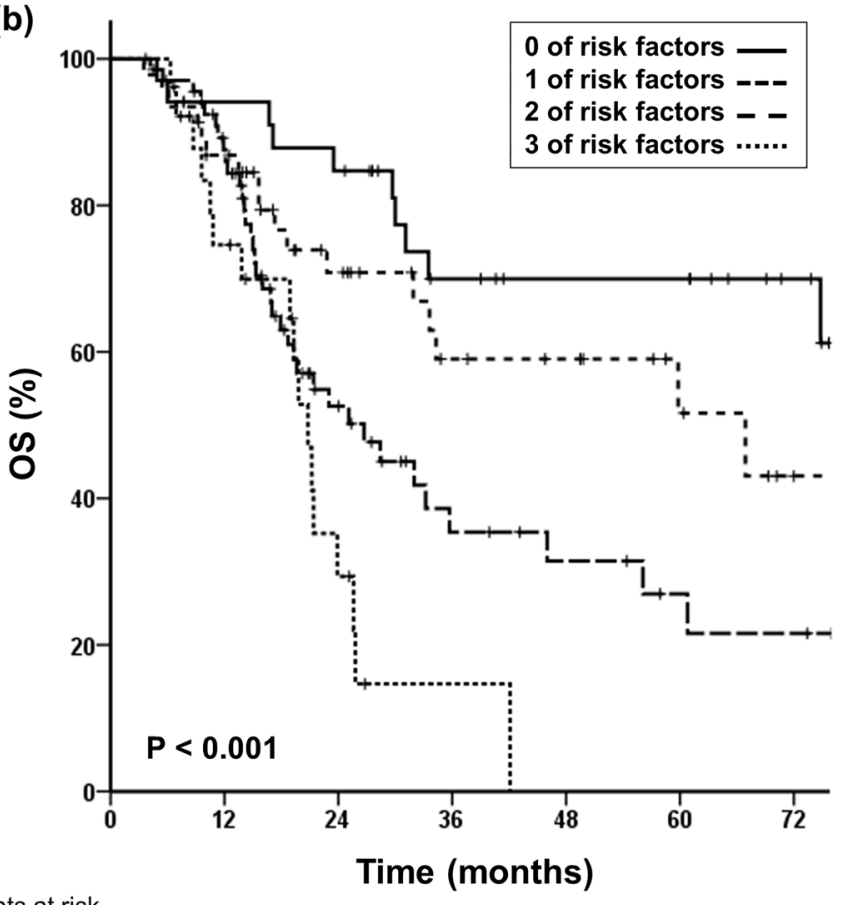

Patients at risk

$\begin{array}{llllllll}\text { Group 0 } & 35 & 30 & 27 & 18 & 15 & 15 & 9 \\ \text { Group 1 } & 46 & 38 & 23 & 14 & 12 & 7 & 2 \\ \text { Group 2 } & 68 & 54 & 22 & 11 & 8 & 5 & 4 \\ \text { Group 3 } & 26 & 17 & 5 & 1 & 0 & 0 & 0\end{array}$

\section{** Included risk factors: Initial CA 19-9, N stage, and perineural invasion}

Fig 2. The number of risk factors is associated with locoregional failure-free survival (LRFFS) and overall survival (OS). Kaplan-Meier curves of (a) Locoregional failure-free survival (LRFFS) and (b) Overall survival (OS) according to the number of risk factors.

doi:10.1371/journal.pone.0157196.g002

benefit most from this approach is not well defined. A well-designed randomized controlled study with modern techniques will be necessary to confirm the efficacy of adjuvant CRT in this population. The RTOG 0848 phase II/III trial is now ongoing to compare gemcitabine together with or without erlotinib hydrochloride and/or radiation therapy after surgery and the result is pending.

In this study, initial CA 19-9 $\geq 200 \mathrm{U} / \mathrm{mL}, \mathrm{N}$ status, PNI, and resection margin were independent risk factors correlated with LRFFS. Preoperative CA 19-9 level has been proven to be an important predictor of recurrence and survival in patients treated with surgical resection through previous studies.[24-26] In our previous study, CA 19-9 level was demonstrated to be an important prognostic factor associated with survival in unresectable or borderline-resectable pancreatic cancer patients treated with CRT.[27] Lymph node metastasis is also one of the most significant predictive factors on survival.[13,26] Hsu et al.[20] analyzed pathologic N1 status as important factor associated with overall survival, and also demonstrated that resection margin was a significant factor predicting survival.

We excluded patients who received neoadjuvant or adjuvant RT with an intention to eliminate any possible effect of radiotherapy on loco-regional failure, which might be a major 
confounding factor. The patients who received adjuvant RT due to positive resection margin were also excluded, which might have induced a selection bias. Fifteen patients with positive resection margins included in this analysis were those who refused adjuvant RT despite their positive resection margin status. Local recurrence was significantly higher in those patients, 9 out of 15 patients (60\%) experienced local recurrence. In this study, resection margin status was also revealed as an independent prognostic factor associated with LRFFS as well as OS.

This study is limited by the nature of its retrospective design. Data for the length of hospital stay, postoperative recovery, and surgical complications were not available for some patients, which might have been a significant influence in deciding their consequent adjuvant treatment. The selection bias may occur in the process of excluding patients treated with adjuvant RT, which was inevitable. The administration of adjuvant chemotherapy and the adjuvant chemotherapy regimens were not homogenous because they were administered according to the clinician.

In conclusion, patients with more than two risk factors among initial CA $19-9 \geq 200 \mathrm{U} / \mathrm{mL}$, $\mathrm{N} 1$ stage, and PNI have a 3.2- to 6.5-fold higher risk of loco-regional failure, as well as a 3.3- to 6 -fold higher risk of death. We suggest that adjuvant local radiotherapy is beneficial to improve the survival outcome of patients with more than two risk factors. To clarify the effect of adjuvant RT, future well-designed randomized controlled studies are needed.

\section{Author Contributions}

Conceived and designed the experiments: JSS. Performed the experiments: HJK JSS. Analyzed the data: HJK JSS. Contributed reagents/materials/analysis tools: HJK WJL CMK HKH SMB SYS JSS. Wrote the paper: HJK JSS.

\section{References}

1. Annual report on the cause of death statistics. 2012.

2. Geer RJ, Brennan MF. Prognostic indicators for survival after resection of pancreatic adenocarcinoma. Am J Surg. 1993; 165: 68-72; discussion 72-63. PMID: 8380315

3. Nitecki SS, Sarr MG, Colby TV, van Heerden JA. Long-term survival after resection for ductal adenocarcinoma of the pancreas. Is it really improving? Ann Surg. 1995; 221: 59-66. PMID: 7826162

4. Brennan MF, Moccia RD, Klimstra D. Management of adenocarcinoma of the body and tail of the pancreas. Ann Surg. 1996; 223: 506-511; discussion 511-502. PMID: 8651741

5. Salem Al, Alfi M, Winslow E, Cho CS, Weber SM. Has survival following pancreaticoduodenectomy for pancreas adenocarcinoma improved over time? J Surg Oncol. 2015; 112: 643-649. doi: 10.1002/jso. 24048 PMID: 26388048

6. Griffin JF, Smalley SR, Jewell W, Paradelo JC, Reymond RD, Hassanein RE, et al. Patterns of failure after curative resection of pancreatic carcinoma. Cancer. 1990; 66: 56-61. PMID: 2354408

7. Westerdahl J, Andren-Sandberg A, Ihse I. Recurrence of exocrine pancreatic cancer-local or hepatic? Hepatogastroenterology. 1993; 40: 384-387. PMID: 8406311

8. Kalser MH, Ellenberg SS. Pancreatic cancer. Adjuvant combined radiation and chemotherapy following curative resection. Arch Surg. 1985; 120: 899-903. PMID: 4015380

9. Further evidence of effective adjuvant combined radiation and chemotherapy following curative resection of pancreatic cancer. Gastrointestinal Tumor Study Group. Cancer. 1987; 59: 2006-2010. PMID: 3567862

10. Klinkenbijl JH, Jeekel J, Sahmoud T, van Pel R, Couvreur ML, Veenhof CH, et al. Adjuvant radiotherapy and 5-fluorouracil after curative resection of cancer of the pancreas and periampullary region: phase III trial of the EORTC gastrointestinal tract cancer cooperative group. Ann Surg. 1999; 230: 776-782; discussion 782-774. PMID: 10615932

11. Smeenk HG, van Eijck CH, Hop WC, Erdmann J, Tran KC, Debois M, et al. Long-term survival and metastatic pattern of pancreatic and periampullary cancer after adjuvant chemoradiation or observation: long-term results of EORTC trial 40891. Ann Surg. 2007; 246: 734-740. PMID: 17968163 
12. Neoptolemos JP, Dunn JA, Stocken DD, Almond J, Link K, Beger H, et al. Adjuvant chemoradiotherapy and chemotherapy in resectable pancreatic cancer: a randomised controlled trial. Lancet. 2001; 358: 1576-1585. PMID: 11716884

13. Neoptolemos JP, Stocken DD, Friess H, Bassi C, Dunn JA, Hickey H, et al. A randomized trial of chemoradiotherapy and chemotherapy after resection of pancreatic cancer. N Engl J Med. 2004; 350 1200-1210. PMID: 15028824

14. National Comprehensive Cancer Network (NCCN). Available: http://www.nccn.org/professionals/ physician_gls/pdf/pancreatic.pdf.

15. Asiyanbola B, Gleisner A, Herman JM, Choti MA, Wolfgang CL, Swartz M, et al. Determining pattern of recurrence following pancreaticoduodenectomy and adjuvant 5 -flurouracil-based chemoradiation therapy: effect of number of metastatic lymph nodes and lymph node ratio. J Gastrointest Surg. 2009; 13: 752-759. doi: 10.1007/s11605-008-0762-x PMID: 19089517

16. Oettle H, Post S, Neuhaus P, Gellert K, Langrehr J, Ridwelski K, et al. Adjuvant chemotherapy with gemcitabine vs observation in patients undergoing curative-intent resection of pancreatic cancer: a randomized controlled trial. Jama. 2007; 297: 267-277. PMID: 17227978

17. Choti MA. Adjuvant therapy for pancreatic cancer-the debate continues. N Engl J Med. 2004; 350: 1249-1251. PMID: 15028829

18. Koshy MC, Landry JC, Cavanaugh SX, Fuller CD, Willett CG, Abrams RA, et al. A challenge to the therapeutic nihilism of ESPAC-1. Int J Radiat Oncol Biol Phys. 2005; 61: 965-966. PMID: 15752874

19. Corsini MM, Miller RC, Haddock MG, Donohue JH, Farnell MB, Nagorney DM, et al. Adjuvant radiotherapy and chemotherapy for pancreatic carcinoma: the Mayo Clinic experience (1975-2005). J Clin Oncol. 2008; 26: 3511-3516. doi: 10.1200/JCO.2007.15.8782 PMID: 18640932

20. Hsu CC, Herman JM, Corsini MM, Winter JM, Callister MD, Haddock MG, et al. Adjuvant chemoradiation for pancreatic adenocarcinoma: the Johns Hopkins Hospital-Mayo Clinic collaborative study. Ann Surg Oncol. 2010; 17: 981-990. doi: 10.1245/s10434-009-0743-7 PMID: 20087786

21. Yeo CJ, Abrams RA, Grochow LB, Sohn TA, Ord SE, Hruban RH, et al. Pancreaticoduodenectomy for pancreatic adenocarcinoma: postoperative adjuvant chemoradiation improves survival. A prospective, single-institution experience. Ann Surg. 1997; 225: 621-633; discussion 633-626. PMID: 9193189

22. Herman JM, Swartz MJ, Hsu CC, Winter J, Pawlik TM, Sugar E, et al. Analysis of fluorouracil-based adjuvant chemotherapy and radiation after pancreaticoduodenectomy for ductal adenocarcinoma of the pancreas: results of a large, prospectively collected database at the Johns Hopkins Hospital. J Clin Oncol. 2008; 26: 3503-3510. doi: 10.1200/JCO.2007.15.8469 PMID: 18640931

23. Rutter CE, Park HS, Corso CD, Lester-Coll NH, Mancini BR, Yeboa DN, et al. Addition of radiotherapy to adjuvant chemotherapy is associated with improved overall survival in resected pancreatic adenocarcinoma: An analysis of the National Cancer Data Base. Cancer. 2015; 121: 4141-4149. doi: 10. 1002/cncr.29652 PMID: 26280559

24. Lundin J, Roberts $P J$, Kuusela $P$, Haglund $C$. The prognostic value of preoperative serum levels of $C A$ 19-9 and CEA in patients with pancreatic cancer. Br J Cancer. 1994; 69: 515-519. PMID: 7510116

25. Hallemeier CL, Botros M, Corsini MM, Haddock MG, Gunderson LL, Miller RC. Preoperative CA 19-9 level is an important prognostic factor in patients with pancreatic adenocarcinoma treated with surgical resection and adjuvant concurrent chemoradiotherapy. Am J Clin Oncol. 2011; 34: 567-572. doi: 10. 1097/COC.0b013e3181f946fc PMID: 21150564

26. Ferrone CR, Finkelstein DM, Thayer SP, Muzikansky A, Fernandez-delCastillo C, Warshaw AL. Perioperative CA19-9 levels can predict stage and survival in patients with resectable pancreatic adenocarcinoma. J Clin Oncol. 2006; 24: 2897-2902. PMID: 16782929

27. Koom WS, Seong J, Kim YB, Pyun HO, Song SY. CA 19-9 as a predictor for response and survival in advanced pancreatic cancer patients treated with chemoradiotherapy. Int J Radiat Oncol Biol Phys. 2009; 73: 1148-1154. doi: 10.1016/j.jrobp.2008.06.1483 PMID: 18760544 